\title{
Feasibility Study of Biogas Production from Miscanthus Biomass in the Tavoush Region
}

\section{Z. Markosyan}

International Center for Agribusiness Research and Education Foundation (ICARE)

davitzmarkosyan@gmail.com

\section{A R T I CLE I N FO}

\section{Keywords:}

economic feasibility,

renewable energy,

Miscanthus,

biogas,

energy security

\begin{abstract}
A B S T RA C T
This study aims to assess the economic feasibility of biogas production from the biomass of Miscanthus Giganteus. Three scenarios have been applied based on its productivity and stand's life. The breakeven prices per tonne for each scenario were calculated and sensitivity analysis was conducted with respect to various factors. Afterward, the cost per gigajoule was calculated and compared to Natural Gas. The cost per gigajoule of Miscanthus ranges from 920-3033 AMD based on the sensitivity results, hence it can be quite cheap alternative depending on the yield, discount rates and rhizome costs.
\end{abstract}

\section{Introduction}

Armenia is a developing country with limited natural and energetic resources. Its population is estimated at around 3 million. The country is not rich in natural resources and currently Agriculture remains the dominant sector in the economy contributing to $12 \%$ of GDP as of 2019 (WB 2019). Armenia has 2.974 million ha of land area, out of which almost 69 percent is considered to be agricultural lands. Around 21.7 percent of the agricultural land is arable (FAO, 2019) which comprises almost 444.8 thousand ha of total land area (NSS 2020). Currently, 15.2 percent of the arable land is concentrated in Ararat Valley. Armenia is not rich in energetic resources; it doesn't have any confirmed oil and natural gas reserves and is not yet active in producing renewable energy, hence, the country is quite dependent on the imported energy resources (UNDP
2017). Along with those energy resources that we currently have, Armenia has a great potential for the sustainable energy because of the presence of hydroelectric and other renewable energy sources.

According to experts, reducing the cost of renewable energy production can help us reduce the import volumes of conventional energy resources (Pasoyan and Sakanyan, 2019).

Renewable energy resources are beneficial and important from different perspectives. First, renewable energy resources help reduce environmental damages, such as the air pollution arising from the usage of conventional energy sources. If the country maintains energy generation from local renewable energy sources, it ensures more price stability with affordable tariffs and avoids being controlled by other countries and regions. This way 
the country ensures its energy and national security. Renewable energy generation would have mainly positive, long-term environmental effects as it reduces the need for power generation based on fossil fuels, thereby reducing Greenhouse Gas (GHG) emissions. One of the widely known energy crops, which are utilized as biomass for energy production is corn, which can be cultivated either solely for biomass generation (green mass) or for eating. Another energy crop, which is not yet famous in Armenia, but can be quite applicable is Miscanthus Giganteus. This study discusses the morphological characteristics of the plant in more detail and its economic feasibility for bioenergy production based on biological and economic research studies already made in Europe, USA, and some other countries, since Miscanthus has never been grown in Armenia.

The origin of Miscanthus is East-Asia, however, its species come from various climatic dimensions including subtropical and tropical, extra warm and cold locations. Miscanthus Giganteus has a great potential for carbon capturing and mitigating the climate change (Virani, 2011). According to the Climate Change Committee each year 23000 hectares would provide 2 million tonnes of $\mathrm{CO}_{2}$ emission savings in the agricultural sector and additionally 11 million tonnes $\mathrm{CO}_{2}$ from the harvested biomass.

In order to understand how competitive Miscanthus is, the net present value method will be used calculating its breakeven price and then the cost per gigajoule will be estimated for comparing it with Natural Gas. If the cost per gigajoule of the energy is cheaper than for Natural Gas, then the opportunity to use the Miscanthus biogas can be attractive, otherwise, the biogas received from that will have no actual demand.

Finally, this study analyzes a twenty-year enterprise budget for Miscanthus to determine the gate breakeven price of the energy crop with three different scenarios depending on its productivity assumptions. The yield of this crop was calculated based on the biophysical characteristics of the crop. Unlike the other studies, the yield and input estimates of this study were based on environmental conditions in Tavush Region, Armenia, which is located in the north-eastern part of Armenia. The average hours of sunshine in Tavush Region is about 1900-2000 hours (Vardanyan, 2016). When getting to know Miscanthus growing locations through the literature, it can be noted that Miscanthus can be grown in this particular region.

\section{Materials and methods}

Miscanthus stands have very few requirements from the soil and that is what makes this grass valuable for the biomass production. Soil in Armenia is not rich in nutrients; that is why additional Nitrogen, Phosphorous and Potassium will be introduced into the soil in its establishment year and onward.

Miscanthus stand is productive for around 20 years. The harvesting starts in the 1st year after the establishment so that it ensures a complete procedure. Usually Miscanthus is harvested in spring and it is harvested only once (Virani, 2011). According to Lewandowski the moisture in Miscanthus drops from $70 \%$ to $20 \%$ in April. Harvesting in spring is also economically more beneficial, since the moisture in the grass increases the cost of harvesting and drying (Lewandowski, 2003). There are some distinct methods for harvesting, but according to European studies the harvesting can be done through a forage harvester, which is also used for harvesting silage maize or any kind of grass.

Miscanthus yield from one hectare can be different depending on the location and climatic conditions. In general, the life expectancy of the Miscanthus stand is around 20 years. This period can be further divided into an increasing yield quantity and flat yield phase. The progressive period is usually 3-5 years and the rest is characterized as flat until 20th year (Virani, 2011). The Miscanthus yield will be assumed as $18 \mathrm{t} / \mathrm{ha}$ in the Republic of Armenia.

The life expectancy of Miscanthus can fluctuate and based on the three scenarios the budget was calculated. The scenario analysis is conducted to understand the changes in breakeven price while changing the life span of the Miscanthus stand. Then a sensitivity analysis will be conducted to see how the changes of the three assumptions will be affecting the breakeven price: yield, rhizome cost and discount rate.

For growing the Miscanthus the basic economic conceptual framework will be applied to understand where the breakeven price stands. Armenia doesn't have a competitive market for the Miscanthus production, however for this study, the assumption would be a competitive market, where each of the producers is trying to maximize his profits. The standard microeconomic theory states, that in the competitive market the Marginal Revenue (MR) should be equal to price and on the other hand, the producer will carry on producing the Miscanthus only if price is equal to the Marginal Cost of producing it (MC).

\section{Scenario A: Best Case Scenario}

Miscanthus stands mature and become fully productive 
in 3-5 years after establishing them and they can be productive up to 15-20 years (Figure 1).

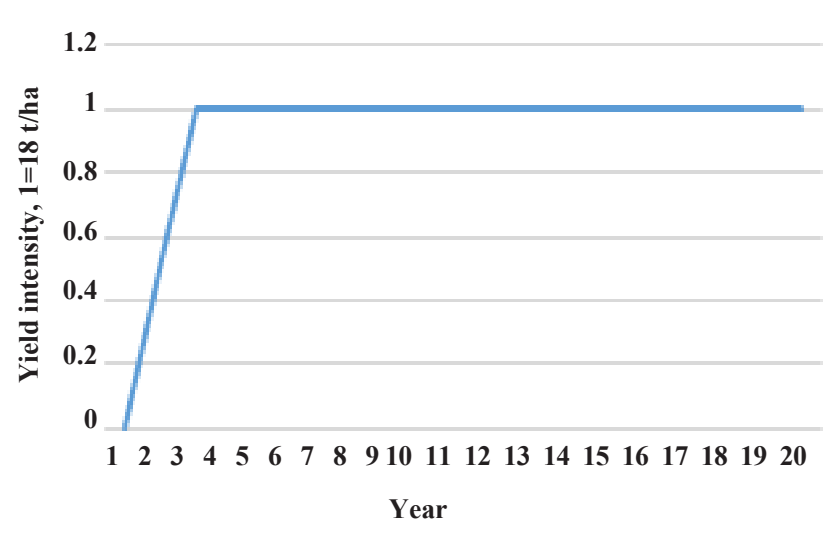

Figure 1. Scenario A - Best Case (composed by the author).

This depends on the climatic conditions, geography and quality of the rhizomes and the human factor of properly taking care of them. For the best case scenario, we assume that the rhizomes are of good quality $(100 \%)$, a full survival of the rhizomes during the winter is observed and all the rhizomes get mature at the end of the second year (50\%). The full productivity of the rhizomes starts from the 3 rd year and lasts for 20 years.

\section{Scenario B: Delayed Harvest Scenario}

For this scenario (Figure 2), we assume that the stand becomes fully productive in 5 years, because of various reasons: resistance of cold weather, improper management, etc. It is worth mentioning that the duration of the stand productivity is still 20 year.

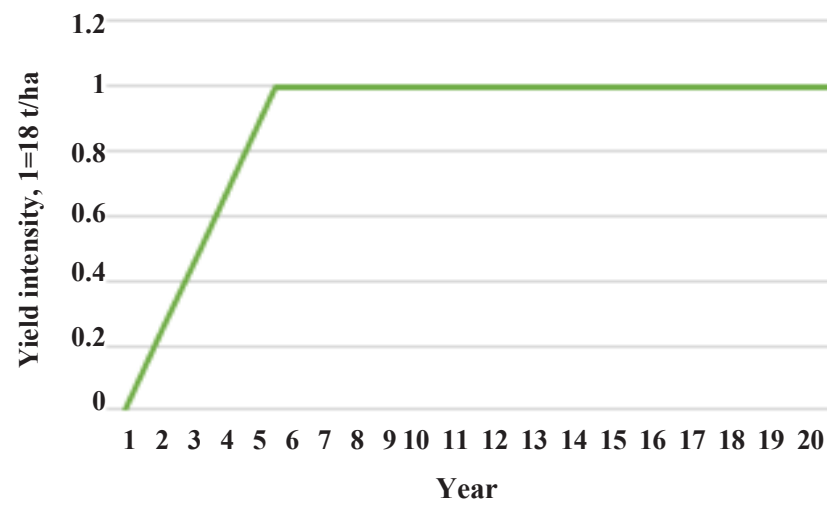

Figure 2. Delayed harvest (composed by the author).

\section{Scenario C: Early Termination}

Since Miscanthus has never been grown in Armenia and there are many factors that can affect its yield capacity, the termination will occur at the 10th year of plant's growth (Figure 3).

\section{Results and discussions}

For this project the following formula has been applied to calculate the NPV for the 20-year Miscanthus:

$$
N P V=\sum_{t=1} \frac{R_{t}}{(1+i)^{t}}-\frac{c_{t}}{(1+i)^{t}} .
$$

NPV of this investment is dependent on the time period in years $(t)$, revenue earned in AMD in the specified time $\left(R_{\mathrm{t}}\right)$ and the total costs in AMD in the time period of $\mathrm{t}\left(C_{\mathrm{t}}\right)$ and the discount rate $(i)$. The discount rate is the time value of money which in its turn is dependent on the risk involved in that specific investment. Since, Miscanthus has never been grown in Armenia, we do not have the market price of the crop for one tonne and since the revenue is a function of price and the yield, we will discount the yield. The breakeven price is determined dividing the sum of the discounted costs by the sum of the discounted yield. In the introduced table (Table 1) the breakeven price is presented for the best case scenario, when Miscanthus is fully productive from the $3 \mathrm{rd}$ year and the stand's life is 20 years. The breakeven price is 29122.2 AMD.

The discount rate of the budget is $17.7 \%$, which has been derived using the formula approach applied by the Research Department of ICARE foundation.

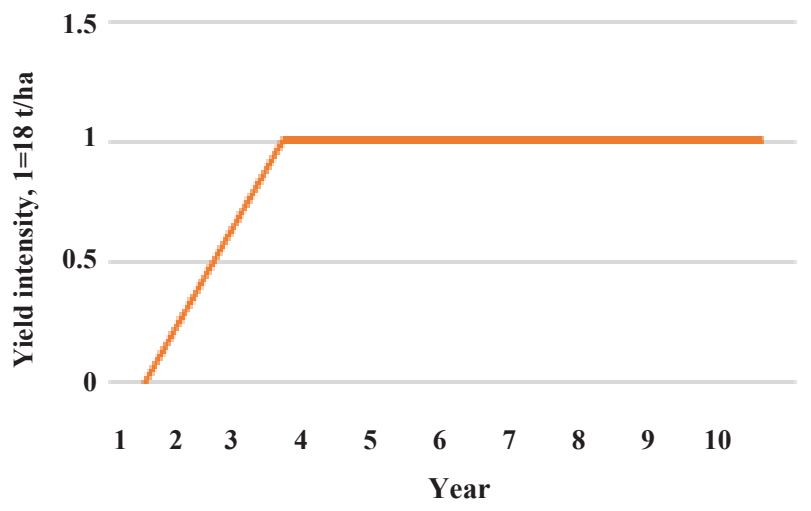

Figure 3. Early termination (composed by the author). 
Table 1. Enterprise Budget for the Scenario A*

\begin{tabular}{|c|c|c|c|c|}
\hline Items/ha & Year 1 & Year 2 & Year 3-20 & Accumulated Costs \\
\hline Land & 30000 & 30000 & 30000 & 600000 \\
\hline Rhizomes & 410000 & & & 41000000 \\
\hline Transportation & 1104000 & & & 110400000 \\
\hline Import Related Administrative Costs & 20000 & & & 2000000 \\
\hline \multicolumn{5}{|l|}{ Establishing Activities and Materials } \\
\hline Tillage & 30000 & & & 3000000 \\
\hline Rental Potato Planter & 30000 & & & 3000000 \\
\hline \multicolumn{5}{|l|}{ Fertilizers } \\
\hline Nitrogen & 72000 & - & - & 72000 \\
\hline Megaflor & & 3750 & 3750 & 71250 \\
\hline \multicolumn{5}{|l|}{ Herbicides } \\
\hline $2.4-\mathrm{D}$ & 4500 & 4500 & 4500 & 90000 \\
\hline \multicolumn{5}{|l|}{ Harvesting } \\
\hline Mowing & & 20000 & 20000 & 380000 \\
\hline Baling & & 33750 & 67500 & 124875000 \\
\hline Spreader & & 10000 & 10000 & 190000 \\
\hline Storage and Transportation & & 22500 & 40000 & 742500 \\
\hline Total Cost & 1700500 & 124500 & 175750 & 4988500 \\
\hline Discounted Costs & 1700500 & 105770.40 & 126865.17 & 2605002.91 \\
\hline Yield & & 9 & 18 & 330 \\
\hline Discounted Yield & & 7.83 & 13.61 & 89.45 \\
\hline Breakeven Price & & & & 29122.2 AMD \\
\hline
\end{tabular}

The following formula has been applied for the calculation of the discount rate, assuming that it is entirely equity financed:

$$
\begin{gathered}
r_{E}=r_{r f_{\text {Armenia }}}+b_{\text {FishFarmCompany }} \\
\times\left(R P_{\text {Mature market }}\right)+A R P_{\text {Country Armenia, }}
\end{gathered}
$$

Where $\boldsymbol{r}_{r f \text { Armenia }}$-Risk-free rate, $\boldsymbol{b}_{\text {FishFarmCompany }}$ - Company's systematic Risk (Beta), $A R P_{\text {CountryArmenia }}$ - Additional country risk premium, $R P_{\text {Mature market }}$ - Market risk premium.

This approach has been suggested by Damodaran, who has calculated country risk and total risk premiums for over 100 countries utilizing the rating agencies' information. For this study the Small Country Risk Premium is considered 0 , hence the discount rate is the following:

$$
r_{E}=7.92 \%+0.95 \times(5.3 \%)+0 \%+4.77 \%=17.7 \% \text {. }
$$

Table 2. Summary of Breakeven Prices*

\begin{tabular}{|l|c|c|c|}
\hline & Scenario A & Scenario B & Scenario C \\
\hline $\begin{array}{l}\text { Breakeven price, } \\
\text { (AMD) }\end{array}$ & 29122.2 & 33134.65 & 32219.1 \\
\hline
\end{tabular}

*Composed by the author.

The Miscanthus stand life for the Scenario B is 20 years, however, Miscanthus becomes fully productive from the 5th year. It is assumed that Miscanthus doesn't provide any biomass in the first year, however, starting from the second year it is starting to produce it with the following proportions: $25 \%, 50 \%, 75 \%, 100 \%$, then it continues to be productive with the same $100 \%$ rate till the 20 th year (Virani, 2011). For the scenario B, all the input costs 
are considered to be the same as for the scenario 1 . With these assumptions, the breakeven price for the scenario was 33134.65 AMD. The breakeven price for this scenario is greater than for the first scenario with around 4000 AMD. For the third case scenario, the breakeven price is calculated as 32 219.1 AMD per tonne, which is less than in the case for the second scenario.

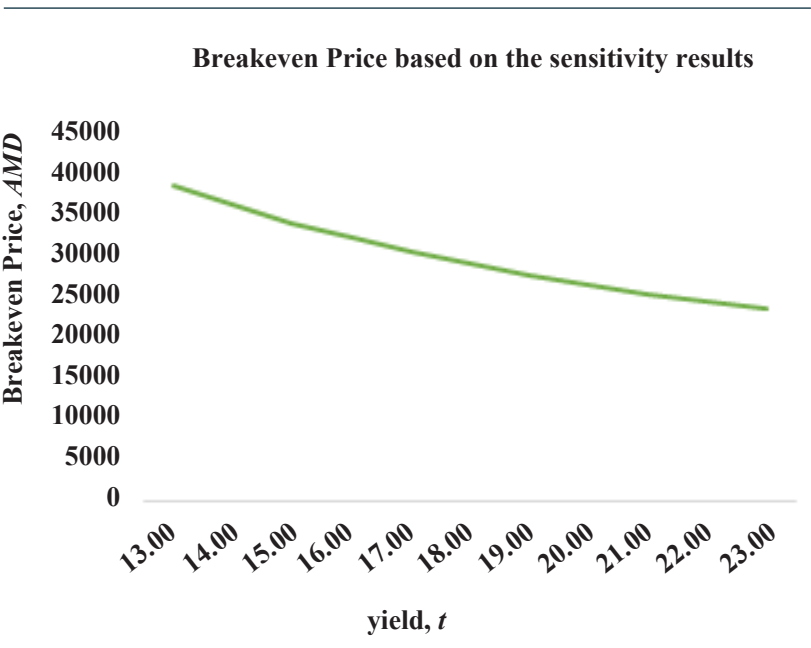

Figure 4. Yield sensitivity results for Scenario A (composed by the author).

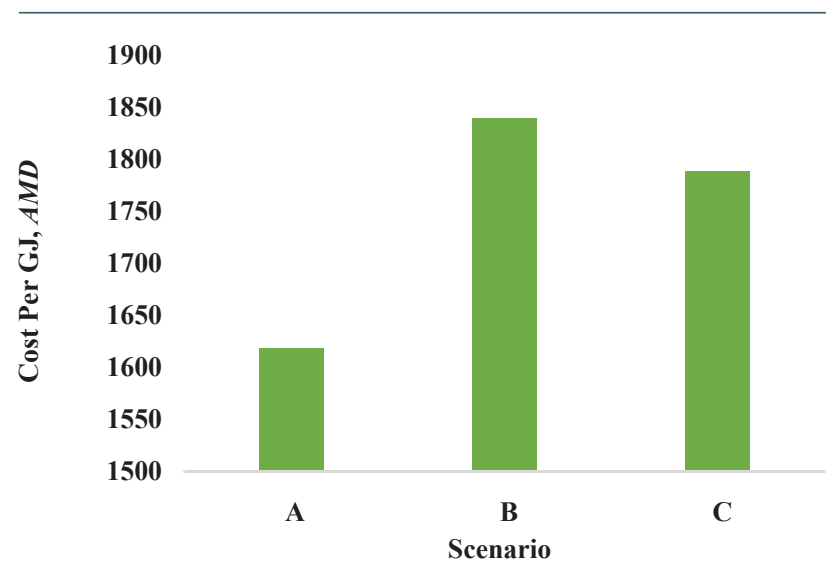

Figure 5. Cost per Gigajoule for Each Scenario (composed by the author).

It is noteworthy that the breakeven prices for three cases are different and the overall picture is presented in Table 2.

When calculating the breakeven farm-gate price of Miscanthus, the change of the yield should be considered. Everything else held constant, the higher Miscanthus yield will deliver lower breakeven prices as presented in Figure 4.

For the best case scenario, the breakeven price with respect to the change of the rhizome costs varies from 27288.84 AMD to 52 039.93 AMD. These numbers are for the case of 24.6 AMD per rhizome and 205 AMD per rhizome respectively.

For the Scenario B, these numbers were 30987.24 AMD and 54.608.82 AMD, and for the Scenario $\mathrm{C}$ the prices were 30 092.95 AMD and 53 486.16 AMD respectively. It is noteworthy, that the change of the rhizome cost influences the breakeven price for the Scenario $\mathrm{C}$ the most. For the discount rate sensitivity analysis, each value differs from its previous one with \pm 3 .

The smallest value in the series is $2.7 \%$ and the breakeven price is 16. 544.52 AMD for the Scenario A. The largest discount rate is $29.7 \%$ and the breakeven price is 42238.33 AMD. For the Scenario B, when discount rate is $29.7 \%$ the breakeven price is 51628.19 AMD and for the Scenario $\mathrm{C}$ the breakeven price is less amounted as 44202.14 AMD. According to the calculations made, compared to the Scenario B, breakeven price in the Scenario $\mathrm{C}$ is smaller when the discount rate is increasing from the base rate.

Since breakeven prices are calculated, the cost per gigajoule and willingness to pay can be derived by the consumers including greenhouse owners. The cost per gigajoule is usually calculated dividing the total cost per tonne of Miscanthus by the energy content of per tonne of Miscanthus (Figure 5). According to the study the energy content of per tonne of Miscanthus is 18 GJ (Shepherd, et al., 2020). For example, in the Scenario A, the base case breakeven price is 29122.22 AMD and whenever this number is divided by $18 \mathrm{GJ}$, we receive the cost per gigajoule as about 1617.9 AMD.

Since the breakeven price of the Scenario B is the largest, so is the cost per gigajoule (1840.81 AMD). As for scenario $\mathrm{C}$, the cost per gigajoule was estimated as 1789.95 AMD.

Because the energy content of Miscanthus is constant, the cost per gigajoule is dependent on the yield of Miscanthus, the rhizome cost, discount rate, etc. The cost per gigajoule was calculated for the yield change from 13-23 t/ha, the rhizome cost from 24.06 - 205 AMD and the discount rate from $2.7 \%-29.7 \%$ for each $3 \mathrm{rd}$ member in the range. After having the calculations done for the cost per gigajoule, the comparison with the price per GJ of Natural Gas will be examined (Table 3 ).

For this study we will only consider the natural gas consumption by the greenhouses, processing companies and large enterprises that consume more than 10000 cubic meters Natural Gas. Since the cost per gigajoule of the Miscanthus for different scenarios and sensitivity is different, the energy value per cubic meter of the Natural 
gas should be calculated. The price per gigajoule for Natural Gas is around 2837 AMD for the greenhouses and other processing organizations. The companies that utilize more than $10000 \mathrm{~m}^{3}$ the cost per GJ is 3243 AMD.

Table 3. Energy Cost Comparison*

\begin{tabular}{l|c|c}
\hline Fuel for Combustion & Miscanthus & Natural Gas \\
\hline Energy Content & $18 \mathrm{GJ} / \mathrm{t}$ & $26.392 \mathrm{~m}^{3}$ \\
\hline Cost Range, AMD & $919.14-3033.82$ & 2837 \\
\hline Average Cost, AMD & 1976 & 2837 \\
*Composed by the author. \\
\hline
\end{tabular}

As shown in the Table 3 the average cost of Miscanthus is cheaper than the Natural gas for the industries that have a ready boiling system in the enterprise.

However, Miscanthus can be either quite cheap alternative for the Natural Gas or very expensive mainly affected by higher discount rates and rhizome costs.

\section{Conclusion}

The objective of this study was to determine the feasibility of growing Miscanthus Giganteus for biogas production and to compare the energy cost with the Natural Gas.

Miscanthus is an ideal perennial energy crop, which is widespread in the European countries, US and in Asian countries. It has low moisture and nutrient content, which is good for the combustions. Miscanthus is famous for its carbon capturing abilities, which is another great advantage among other energy crops. Besides, it can also be grown in Marginal lands and not compete with other crops. The plant is not invasive and it is sterile.

Miscanthus Giganteus has never been grown in Armenia; hence the literature review was applied to derive its morphological characteristics and build an enterprise budget. Three main scenarios were developed depending on its productivity and the stand duration.

For all three scenarios the breakeven price per hectare was calculated. Later, based on the breakeven price, the cost per gigajoule was calculated and compared to the cost per gigajoule of the Natural Gas.

The base case breakeven prices for all of the three scenarios are 29 122.25 AMD, 33 134.65 AMD and 32 219.06 AMD. The lowest breakeven price among all the three scenarios is in the Scenario A. According to the sensitivity results, the bigger the yield of Miscanthus, the less the breakeven price for per tonne of Miscanthus is and vice versa.
In addition, the cost per gigajoule of Miscanthus ranges from 919.14 - 3033.82 AMD, price per gigajoule of the natural gas is 2837 AMD; hence as long as the price is lower than that, producing Miscanthus for biogas production is feasible.

In this research study it has been assumed that the industries which will buy Miscanthus for the biogas production have a boiler system. However, it is important to calculate the capital expenditures for the boiler construction. As long as the price difference of Miscanthus and Natural Gas is bigger enough to offset the cost of the boiler construction, the biogas production from Miscanthus biomass can be feasible solution. It is important to conduct research based on the real case studies through the pilot programs. This will enable to have a better understanding and precise details about the establishment process, caring activities, biomass yield, etc.

\section{References}

1. FAO 2019. http://www.fao.org/armenia/fao-in-armenia/ armenia-at-a-glance/fr/ (accessed on 16.04.2021).

2. Lewandowski, I. (2003). The Development and Current Status of Perennial Rhizomatous Grasses as Energy Crops in the US and Europe // Biomass and Bioenergy.

3. NSC 2020. Agriculture. Yearbook. https://www.armstat. am/file/doc/99520943.pdf (accessed on 29.02.2021).

4. Pasoyan, A., Sakanyan, N. (2019). Energy Demand, Supply and Efficiency in Rural Armenia: Baseline Data Collection and Analysis. Yerevan: GIZ.

5. Shepherd, A., Littleton, E., Clifton-Brown, J., Mike, M. and Astley, H. (2020). Projections of Global and UK Bioenergy Potential from Miscanthus $\times$ GiganteusFeedstock Yield, Carbon Cycling and Electricity Generation in the 21st century. Article.

6. UNDP 2017. Feasibility Study of Biogas Production http://www.natureic.am/Content/announcements/10538/FS Biogas\%20Potential_final.pdf (accessed on 29.02.2021).

7. Vardanyan, E. (2016). The Indicators Characterizing Alterations of Tavush Region Natural Landscapes.

8. Virani, T. (2011). The Economic Feasibility of Bioenergy Production from Miscanthus for the Ontario Greenhouse Industry. Master Thesis.

9. WB 2019. The World Bank Data https://data.worldbank. org/indicator/NV.AGR.TOTL.ZS?locations=AM (accessed on 20.02.2021). 